\title{
Cardiac involvement in hereditary myopathy with early respiratory failure
}

\author{
A cohort study \\ OPEN
}

Hannah E. Steele, MRCP Elizabeth Harris, MRCP Rita Barresi, PhD Julie Marsh, MSc Anna Beattie, FRCR John P. Bourke, MD Volker Straub, MD

Patrick F. Chinnery, FRCP, FMedSci

Correspondence to Dr. Chinnery: pfc25@medschl.cam.ac.uk

\section{ABSTRACT}

Objective: To assess whether hereditary myopathy with early respiratory failure (HMERF) due to the c.951434T>C; (p.Cys31712Arg) TTN missense mutation also includes a cardiac phenotype.

Method: Clinical cohort study of our HMERF cohort using ECG, 2D echocardiogram, and crosssectional cardiac imaging with MRI or CT.

Results: We studied 22 participants with the c.951434T>C; (p.Cys31712Arg) TTN missense mutation. Three were deceased. Cardiac conduction abnormalities were identified in 7/22 (32\%): sustained atrioventricular tachycardia $(n=2)$, atrial fibrillation $(n=2)$, nonsustained atrial tachycardia $(n=1)$, premature supraventricular complexes $(n=1)$, and unexplained sinus bradycardia ( $n=1$ ). In addition, 4/22 (18\%) had imaging evidence of otherwise unexplained cardiomyopathy. These findings are supported by histopathologic correlation suggestive of myocardial cytoskeletal remodeling.

Conclusions: Coexisting cardiac and skeletal muscle involvement is not uncommon in patients with HMERF arising due to the c.951434T>C; (p.Cys31712Arg) TTN mutation. All patients with pathogenic or putative pathogenic TTN mutations should be offered periodic cardiac surveillance. Neurology ${ }^{\circledR}$ 2016;87:1031-1035

\section{GLOSSARY}

HMERF = hereditary myopathy with early respiratory failure; LV = left ventricular; MFM = myofibrillar myopathy; NIV = noninvasive ventilation; $\mathbf{R V}=$ right ventricular

Hereditary myopathy with early respiratory failure (HMERF) is an autosomal dominant disorder arising due to missense mutations in the fibronectin III domain of the TTN gene, most commonly c.951434T $>$ C; (p.Cys31712Arg). ${ }^{1}$ HMERF is characterized by adult onset of distal or proximal muscle weakness in association with early respiratory muscle weakness, which may be the presenting feature and require noninvasive ventilation. Muscle biopsy findings are largely nonspecific, although myofibrillar myopathy and cytoplasmic bodies are described. ${ }^{2}$

Other skeletal myopathies caused by missense mutations in titin include tibial muscular dystrophy due to heterozygous mutations in the C-terminus ${ }^{3}$ and limb-girdle muscular dystrophy type $2 \mathrm{~J}$ arising from recessive mutations at the same locus. ${ }^{4}$ Cardiac complications in these phenotypes have not been reported previously. ${ }^{1,3-5}$ Conversely, heterozygous truncating TTN mutations are a recognized cause of dilated ${ }^{6}$ and restrictive ${ }^{7}$ cardiomyopathies without apparent skeletal muscle involvement. However, the rare coexistence of skeletal and cardiac muscle disease in recessive truncating titin mutations ${ }^{6}$ raises the possibility that cardiac involvement may occur in other titinopathies. This has implications for the surveillance of those at risk. To address this, we carried out the first systematic cardiac study in HMERF using multimodal structural and functional cardiac imaging.

From the John Walton Muscular Dystrophy Research Centre (H.E.S., E.H., R.B., J.M., V.S.), Newcastle University; Department of Cardiology (A.B., J.P.B.), Freeman Hospital, NUTH NHS Foundation Trust; Medical Research Council Mitochondrial Biology Unit (P.F.C.); and Department of Clinical Neurosciences (P.F.C.), School of Clinical Medicine, University of Cambridge, UK.

Go to Neurology.org for full disclosures. Funding information and disclosures deemed relevant by the authors, if any, are provided at the end of the article. The Article Processing Charge was paid by the Wellcome Trust.

This is an open access article distributed under the terms of the Creative Commons Attribution License 4.0 (CC BY), which permits unrestricted use, distribution, and reproduction in any medium, provided the original work is properly cited. 


\begin{tabular}{|c|c|c|c|c|c|c|c|c|c|c|c|c|}
\hline \multirow{2}{*}{\multicolumn{2}{|c|}{$\begin{array}{l}\text { Patient } \\
\text { and } \\
\text { family ID }\end{array}$}} & \multirow[b]{2}{*}{ Sex } & \multirow{2}{*}{$\begin{array}{l}\text { Age at } \\
\text { onset, } y\end{array}$} & \multirow[b]{2}{*}{ DisD, y } & \multirow[b]{2}{*}{ Skeletal muscle pattern } & \multirow[b]{2}{*}{ Function } & \multicolumn{2}{|c|}{$\begin{array}{l}\text { PFTs (\% } \\
\text { predicted) }\end{array}$} & \multirow[b]{2}{*}{ NIV } & \multirow[b]{2}{*}{ Cardiac $\mathrm{Hx}, \mathrm{Ix}$, and $\mathrm{Mx}$} & \multirow[b]{2}{*}{ 12-Lead ECG } & \multirow[b]{2}{*}{ Echo summary } \\
\hline & & & & & & & $\mathrm{FEV}_{1}$ & FVC & & & & \\
\hline 1 & A & $\mathrm{F}$ & 30 & 14 & Distal LL & Unaided & 72 & 71 & $\mathrm{~N}$ & No medication & Low-amplitude $\mathrm{p}$ waves & $\begin{array}{l}\text { Segmental LV hypokinesis } \\
\text { and } \downarrow L V E F 50 \%-55 \%\end{array}$ \\
\hline 2 & B & M & 37 & 6 & Distal > proximal LL > UL & AFO & 52 & 68 & $\mathrm{~N}$ & Ramipril for high BP & Normal & Normal \\
\hline 3 & B & M & 33 & 13 & Distal and proximal $\mathrm{LL}$ and distal $\mathrm{UL}$ & Unaided & 83 & 85 & $\mathrm{Y}$ & No medication & Normal & Grade 1 DD-NFA \\
\hline 4 & B & $\mathrm{F}$ & 40 & 10 & Distal and proximal $U L$ and $L L$ and axial & Unaided & uk & 53 & $\mathrm{~N}$ & $\begin{array}{l}\text { Propranolol intermittently; } \\
24 \text {-hour ECG = } 11 \text { beats AT }\end{array}$ & $\begin{array}{l}\text { Tachycardic with premature } \\
\text { atrial ectopics }\end{array}$ & $\begin{array}{l}\text { E-E' 8-15, possible diastolic } \\
\text { LV dysfunction }\end{array}$ \\
\hline 5 & B & M & 45 & 2 & Mild distal UL and LL & Unaided & 67 & 70 & $\mathrm{~N}$ & $\begin{array}{l}\text { Palpitations; no meds; 24-hour } \\
\text { ECG = normal }\end{array}$ & Normal & Normal \\
\hline 6 & B & $\mathrm{F}$ & 60 & 14 & Mild distal LL weakness & Unaided & 67 & 62 & $\mathrm{~N}$ & No medication & Bradycardic: 55 bpm & $\begin{array}{l}\text { E-E' 8-15, possible diastolic } \\
\text { LV dysfunction }\end{array}$ \\
\hline 7 & B & M & 16 & 32 & Distal and proximal LL; distal UL & Stick & uk & 73 & $\mathrm{~N}$ & No medication & Notched $p$ waves & Poor view \\
\hline 8 & B & $\mathrm{F}$ & 29 & 14 & Distal and proximal LL & Unaided & 70 & 64 & $\mathrm{Y}$ & AVNRT: ablation; no meds & Normal & Normal (LV EF low normal 55\%) \\
\hline 9 & B & M & 35 & 30 & Distal and proximal UL and LL & WC & 33 & 32 & $\mathrm{Y}$ & Lisinopril for high BP & Premature SV complexes & Grade 1 DD-NFA \\
\hline 10 & B & M & 44 & 15 & Distal and proximal UL and LL & WC & 67 & 63 & $\mathrm{Y}$ & Palpitations; atorvastatin & Normal & Small LV cavity \\
\hline 11 & B & M & 20 & 34 & Distal and proximal UL and LL & Crutch and AFO & 57 & 55 & $\mathrm{~N}$ & $\begin{array}{l}\text { 2012: Perindopril } 4 \text { mg, } \\
\text { bisoprolol } 2.5 \mathrm{mg} \text {; } 2014 \text { : } \\
\text { perindopril } 4 \mathrm{mg} \text {, bisoprolol } \\
5 \mathrm{mg}\end{array}$ & $\begin{array}{l}\text { Low-amplitude } p \text { waves, } \\
\text { normal PR, flattened T } \\
\text { waves (evolving over } \\
2 \text { years) }\end{array}$ & $\begin{array}{l}\text { 2012: LV EF 40\%-45\%; mild- } \\
\text { moderate imp RV; } 2013 \text { : LV EF } \\
50 \% \text {; 2014: LV EF > 55\%, low } \\
\text { normal RV function, segmental } \\
\text { CM; 2015: LV EF 50\% }\end{array}$ \\
\hline 12 & B & $\mathrm{F}$ & 46 & 10 & Distal and proximal LL; distal UL & WC & 73 & 71 & $\mathrm{~N}$ & No medication & Premature atrial complexes & Normal \\
\hline 13 & C & M & 35 & 6 & Distal and proximal LL; proximal UL & WC & uk & 77 & $\mathrm{~N}$ & No medication & $\begin{array}{l}\text { Low-amplitude notched } p \\
\text { waves, nonspecific flattened } \\
\text { T waves (evolving over } 3 \text { years) }\end{array}$ & $\begin{array}{l}\text { 2014: LV EF 50\%; 2015: LV } \\
\text { EF 55\% }\end{array}$ \\
\hline 14 & C & $\mathrm{F}$ & NA & NA & Nil & Unaided & uk & 77 & $\mathrm{~N}$ & No medication & Normal & Normal \\
\hline 15 & D & M & 28 & 5 & Distal and proximal UL and LL & AFO & uk & 70 & $\mathrm{~N}$ & No medication & Normal & Normal \\
\hline 16 & E & M & 30 & 27 & Distal LL and UL & uk & uk & 68 & $\mathrm{~N}$ & No medication & uk & Normal \\
\hline 17 & $\mathrm{~F}$ & M & 39 & 8 & Distal LL and UL & uk & uk & uk & uk & No medication & Normal & Normal \\
\hline 18 & G & M & 27 & 15 & Distal and proximal $\mathrm{LL}>$ distal UL & AFO & 55 & 56 & $\mathrm{~N}$ & No medication & uk & Normal \\
\hline 19 & $\mathrm{H}$ & M & 30 & 33 & Distal LL and UL & uk & uk & 56 & $\mathrm{Y}$ & SVT; bisoprolol & uk & uk \\
\hline $20 *$ & I & M & 45 & 4 & Proximal and distal $\mathrm{LL}$; proximal UL & Stick & 67 & 71 & $\mathrm{~N}$ & No cardiac hx or medication & uk & uk \\
\hline $21 *$ & $\mathrm{~J}$ & M & uk & uk & Proximal and distal LL; mild proximal UL & uk & uk & uk & $\mathrm{Y}$ & PPM, AVR; uk medication & Atrial fibrillation & uk \\
\hline $22 *$ & C & M & 44 & 30 & Distal $>$ proximal $\mathrm{LL}>\mathrm{UL}$ & WC & 33 & 27 & $\mathrm{Y}$ & $\begin{array}{l}\text { 2010: Bisoprolol } 2.5 \mathrm{mg} \text {; } \\
\text { furosemide } 20-40 \mathrm{mg} \text {; } 24 \text {-hour } \\
\text { ECG: AF with variable rate }\end{array}$ & Atrial fibrillation & $\begin{array}{l}\text { 2007: LV EF 45\%-50\%; 2013: } \\
\text { LV EF 50\% }\end{array}$ \\
\hline
\end{tabular}

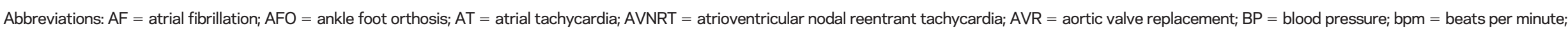

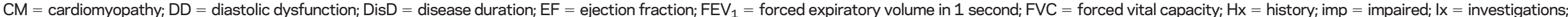

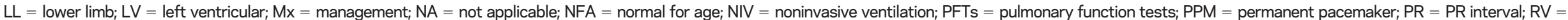
right ventricular; SVT = supraventricular tachycardia; UL = upper limb; uk = unknown; WC = wheelchair; * = deceased patients. 
METHODS All participants known to the John Walton Muscular Dystrophy Research Centre, Newcastle upon Tyne, United Kingdom, with the c.951434T >C; (p.Cys31712Arg) TTN missense mutation had a 12-lead ECG and echocardiogram requested as part of routine clinical care. All available cardiac test results were reviewed. Thereafter, all participants residing within the North East of England were invited to attend for a cardiac MRI, irrespective of cardiac symptomatology or initial findings. Where participants were unable to tolerate MRI, cardiac CT scan was offered.

All cardiac MRIs were performed on a $1.5 \mathrm{~T}$ Siemens MRI scanner using a standardized cardiomyopathy protocol, with black blood anatomical, multiplanar short tau inversion recovery, multiplanar cines-including short axis stack for ventricular function, multiplanar cines, and delayed enhancement sequences obtained with gadoterate meglumine (Dotarem; Guerbet, Villepinte, France). All cardiac CT imaging was performed on a Siemens dual source CT scanner retrospectively gated at low dose for functional information only with a Flash mode delayed enhancement series 7 minutes following iohexol (Omnipaque; GE Healthcare, Cleveland, $\mathrm{OH}$ ) administration.

Histopathologic correlation. Based on previous reports of desmin as a marker of cardiac dysfunction, ${ }^{8}$ we undertook analysis of frozen myocardial samples collected postmortem from 3 patients with HMERF.

Immunohistochemistry. Immunolabeling for $\beta$-spectrin (clone RBC2/3D5), desmin (DAKO M0760; Glostrup, Denmark), myotilin (NCL-Myotilin; Leica Biosystems, Newcastle, UK), VCP (BD Biosciences, East Rutherford, NJ), ubiquitin (NCL-UBIQm; Leica Biosystems), and p62 (Abcam ab56416; Cambridge, UK) was undertaken.
Western blot. Myocardial samples from patients and agematched controls with no reported cardiac pathology were homogenized and run on sodium dodecyl sulfate polyacrylamide gel electrophoresis ( $4 \%-12 \%$ gradient). Immunoanalysis was performed using the antibody against desmin. Immunoblots were visualized with SuperSignal West Pico Chemiluminescent Substrate detection using AlphaInnotech FluorChem Q platform and AlphaView software v3.0. All tests were performed in duplicate.

Standard protocol approvals, registrations, and patient consents. Clinical assessments were undertaken as routine clinical care. Consent and ethical approval was in place for the histopathologic studies.

RESULTS We identified 22 participants with the c.951434T >C; (p.Cys31712Arg) TTN mutation. Three were deceased. Eighteen attended for echocardiogram, of whom 6 subsequently had cardiac MRI and 4 cardiac CT imaging. Two individuals failed to attend planned MRI scans. Cross-sectional imaging was not requested in 7 patients due to geographic dispersion. Clinical features are outlined in table 1.

We identified conduction abnormalities in 32\% (7/22) of patients. These included sustained atrioventricular tachycardia $(8 \mathrm{~B}$ and $19 \mathrm{H})$, nonsustained atrial tachycardia (4B; figure, A), premature supraventricular complexes (9B), unexplained sinus bradycardia (6B), and atrial fibrillation $(21 \mathrm{~J}$ and $22 \mathrm{C})$. Patients $8 \mathrm{~B}$ and $19 \mathrm{H}$ were treated with bisoprolol and $8 \mathrm{~B}$ underwent catheter ablation. Patients 5B and 10B had a history of
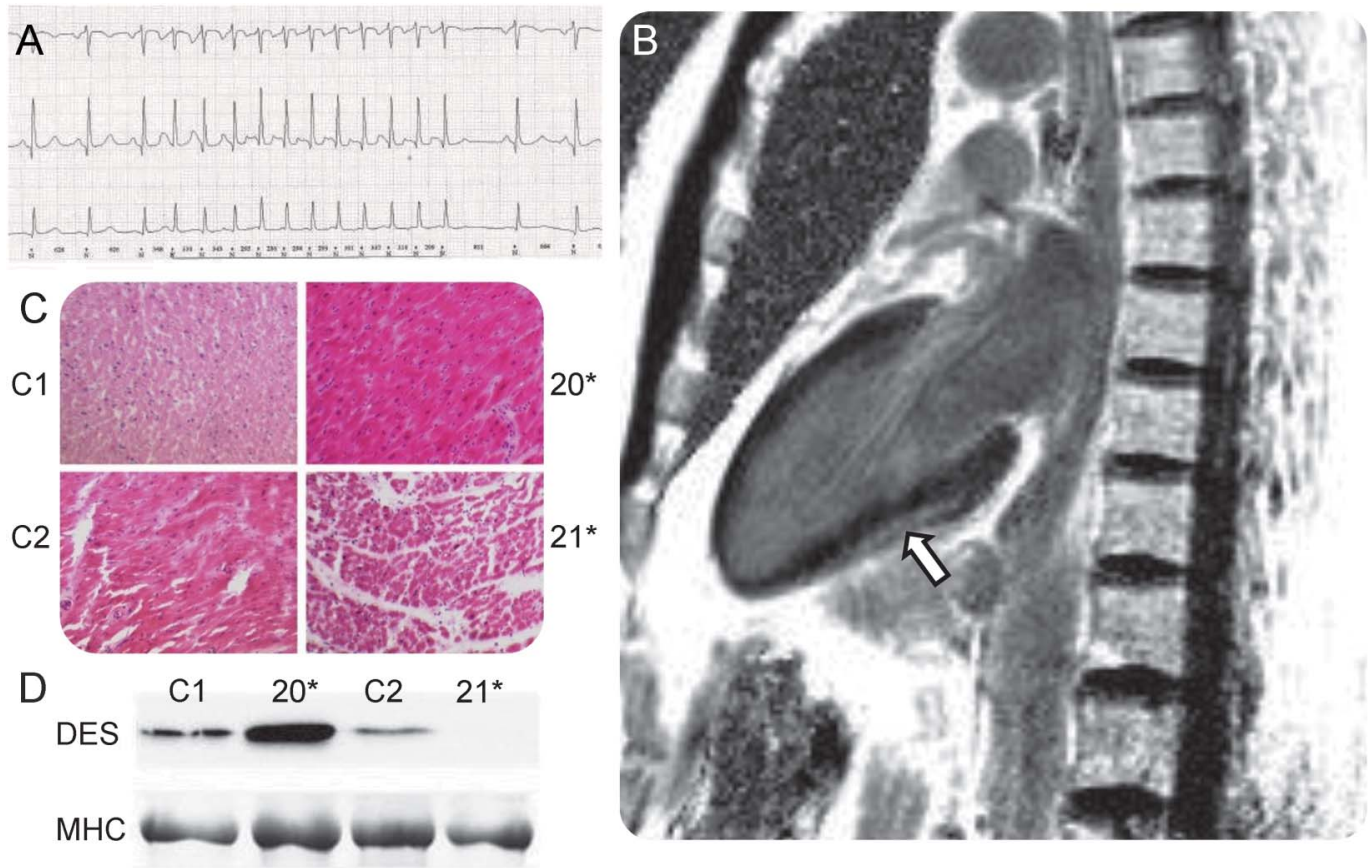

(A) Twenty-four-hour ECG demonstrates nonsustained atrial tachycardia (patient 4B). (B) Cardiac MRI of 11B demonstrates subepicardial fibrosis (arrow). (C) Hematoxylin \& eosin staining of myocardium in controls (C1 and C2) and patients with HMERF (20* and 21*). (D) Western blot staining for desmin (DES) and myosin heavy chain (MHC). 
Table 2 Cardiac MRI and CT features

\begin{tabular}{|c|c|c|c|c|c|c|c|c|}
\hline $\begin{array}{l}\text { Patient } \\
\text { and } \\
\text { family }\end{array}$ & ID & Ix & $\begin{array}{l}\text { RV: Ejection } \\
\text { fraction, \% }\end{array}$ & $\begin{array}{l}\text { LV: Ejection } \\
\text { fraction, \% }\end{array}$ & Fibrosis? & $\begin{array}{l}\text { Corrected end } \\
\mathrm{LV} \text { diastolic } \\
\text { volume, } \mathrm{mL} / \mathrm{m}^{2}\end{array}$ & $\begin{array}{l}\text { Corrected end } \\
\mathrm{RV} \text { diastolic } \\
\text { volume, } \mathrm{mL} / \mathrm{m}^{2}\end{array}$ & Overall impression \\
\hline 1 & $A$ & MRI & 44 & 60 & $\mathrm{~N}$ & $51(56-96)$ & $63(48-112)$ & $\begin{array}{l}\text { (1) Subtle dyssynchronous ventricular } \\
\text { contractions; (2) mild RV impairment }\end{array}$ \\
\hline 2 & B & MRI & 64 & 70 & $\mathrm{~N}$ & $56(57-105)$ & $59(61-121)$ & Normal \\
\hline 5 & B & СТ & 57 & 60 & $\mathrm{~N}$ & & & Normal \\
\hline 7 & & MRI 2012 & 38 & 45 & $\mathrm{~N}$ & $90(57-105)$ & 109 (61-121) & $\begin{array}{l}\text { Possible early cardiomyopathy: LVEF and } \\
\text { LV volume in URN; no medication }\end{array}$ \\
\hline 8 & $B$ & MRI & 56 & 57 & $\mathrm{~N}$ & $70(56-96)$ & $69(48-112)$ & Normal \\
\hline 9 & B & СT & & 63 & $\mathrm{~N}$ & & & Normal \\
\hline
\end{tabular}

Abbreviations: IX = investigations; LV = left ventricle; LVEF = left ventricular ejection fraction; PA = pulmonary artery; RV = right ventricle; URN = upper range of normal.

palpitations without specific diagnosis being reached despite investigation.

Asymptomatic global left ventricular systolic dysfunction was evident in 4/22 (18\%) patients (1A, $11 \mathrm{~B}, 13 \mathrm{C}$, and $22^{*}$ ) on echocardiogram (tables 1 and 2). Although none had chamber dilation, the findings were compatible with nonischemic cardiomyopathy. Two were known to have reduced left ventricular (LV) ejection fraction at study onset (11B and 13C), and one was identified with mild right ventricular (RV) systolic dysfunction in the course of the study (1A). We identified subepicardial fibrosis in $11 \mathrm{~B}$ on late gadolinium-enhanced MRI (figure, B). None had other lifestyle, history, or medical risk factors to explain their cardiac features.

Four individuals had evidence of possible or definite LV diastolic dysfunction by $\mathrm{E}-\mathrm{E}^{\prime}$ measures on echocardiography. Patient 9B was on maintenance lisinopril for hypertension, but none of the others (3B, 4B, 6B) had any history of cardiac disease, cardioactive medication use, or prior cardiology assessment. Patients 6B and 9B underwent cross-sectional cardiac imaging with $\mathrm{CT}$ and mild diastolic impairment was confirmed in 6B (tables 1 and 2).

Response to treatment. Participant $11 \mathrm{~B}$ demonstrated sustained improvement in cardiac function in the 2012-2015 period following initiation of perindopril and bisoprolol therapy. Left ventricular function improved in patient $22 *$ after commencing $\beta$-blocker therapy (table 1).

Relationship to disease onset. The age range of individuals developing cardiomyopathy overlapped with those without (40-65 and 33-65 years, respectively) and with disease duration (6-34 and 2-33 years, respectively). Cardiomyopathy emerged 4-30 years after first skeletal muscle symptoms (table 1).

Relationship to respiratory disease. We assessed the relationship of confirmed ventricular systolic dysfunction at any time with respiratory disease and noninvasive ventilation (NIV) use. No relationship was identified between ventricular systolic impairment and respiratory disease (reduction in pulmonary function tests of $25 \%$ or more from predicted) or use of NIV ( $p=0.2722$ and $p=0.2778$, respectively; Fisher exact test).

Histopathologic correlation. Immunohistochemistry. Myocardial tissue preservation was satisfactory in patient 20 *, degraded in patient $21 *$ (figure, C), and unsuitable for further analysis in patient $22 *$. Immunolabeling for myofibrillar proteins was unremarkable and did not demonstrate abnormal protein accumulation (not shown).

Immunoblot. Desmin expression was upregulated (approximately 2.5-fold) in patient $20^{*}$ compared to controls, suggesting myocardial cytoskeletal remodeling. ${ }^{8}$ Patient $21^{*}$ showed reduced desmin expression consistent with extensive postmortem delay (figure, D).

DISCUSSION Our findings show that cardiac involvement is not uncommon in patients with the c.951434T > C (p.Cys31712Arg) TTN missense mutation. Conduction abnormalities occurred in a third of patients, with atrial fibrillation and sustained paroxysmal atrioventricular tachycardia most frequently identified (2/22; $9 \%$ each). The prevalence of the latter arrhythmia 
is significantly higher than seen in the general population $\left(9 \%\right.$ vs $0.2 \% ; p=0.0026$; Fisher exact test). ${ }^{9}$

Additionally, cardiomyopathy was identified in $18 \%$ (4/22). Importantly, this was responsive to standard cardioactive therapies. Interestingly, the presence of either LV or RV dysfunction was independent of respiratory failure, suggesting the mechanism is not secondary to nocturnal hypoventilation, restrictive pulmonary physiology, or cor pulmonale. The etiology of the diastolic dysfunction observed is uncertain given the absence of LV hypertrophy or significant fibrosis. Diastolic dysfunction is a recognized feature of cardiovascular aging and consequently, is the most likely explanation for our findings. However, a diseasespecific association cannot be excluded.

As a recently recognized cause of myofibrillar myopathy (MFM), the TTN mutation causing HMERF is now included in genetic testing panels for MFM. ${ }^{2}$ Cardiac involvement in other myofibrillar myopathies, also encompassing arrhythmia and cardiomyopathy, is well-recognized, with an estimated prevalence of $30 \% .{ }^{10}$ Our findings are in keeping with this.

The main limitation of our study is its pragmatic nature as it was conducted in the context of routine clinical health care. Consequently, the echocardiograms were performed and reported by several—albeit experienced-echo-technicians and the CT scans were reported retrospectively. While MRI remains the gold standard investigation for assessment of ventricular function, use of CT in this population, with neuromuscular respiratory failure and NIV, enabled more patients to undergo cross-sectional cardiac imaging. Although the 2 modalities are not directly comparable, where imaging is undertaken longitudinally using the same method, an assessment of change can be made.

As the full spectrum of cardiac and skeletal muscle phenotypes associated with TTN mutations remains unknown, patients with pathogenic or putative pathogenic TTN mutations should be offered periodic cardiac surveillance. However, based on the findings we present here, some of the observed abnormalities may be due to normal aging, and not TTN cardiomyopathy per se.

\section{AUTHOR CONTRIBUTIONS}

Dr. Steele: wrote the first draft manuscript, study coordination, acquisition of data, interpretation of data. Dr. Harris: drafting manuscript, study coordination, acquisition of data, interpretation of data. Dr. Barresi: revising manuscript for content, acquisition of data, analysis of data, interpretation of data. J. Marsh: acquisition of data. Dr. Beattie: revising manuscript for content, interpretation of data. Dr. Bourke: revising manuscript for content, interpretation of data. Prof. Straub: study concept and design, acquisition of data, study supervision, revising manuscript for content. Prof. Chinnery: study concept and design, acquisition of data, analysis, interpretation, study supervision, wrote the first draft manuscript.

\section{ACKNOWLEDGMENT}

The authors thank the patients, cardiac technicians, and radiographers for their assistance in screening patients. Direct sequencing of the common HMERF missense mutation c.951434T >C; (p.Cys31712Arg) was performed by the Northern Genetics Service. Mutations are reported using the reference sequence NM_001267550.1.

\section{STUDY FUNDING}

P.F.C. is a Wellcome Trust Senior Fellow in Clinical Science (101876/ Z/13/Z) and a UK NIHR Senior Investigator who receives support from the Medical Research Council Mitochondrial Biology Unit (MC_UP_1501/2), the Wellcome Trust Centre for Mitochondrial Research (096919Z/11/Z), the Medical Research Council (UK) Centre for Translational Muscle Disease research (G0601943), EU FP7 TIRCON, and the National Institute for Health Research (NIHR) Biomedical Research Centre based at Cambridge University Hospitals NHS Foundation Trust and the University of Cambridge. The views expressed are those of the authors and not necessarily those of the NHS, the NIHR, or the Department of Health.

\section{DISCLOSURE}

The authors report no disclosures relevant to the manuscript. Go to Neurology.org for full disclosures.

Received January 25, 2016. Accepted in final form May 26, 2016.

\section{REFERENCES}

1. Pfeffer G, Elliott HR, Griffin $\mathrm{H}$, et al. Titin mutation segregates with hereditary myopathy with early respiratory failure. Brain 2012;135:1695-1713.

2. Pfeffer G, Barresi R, Wilson IJ, et al. Titin founder mutation is a common cause of myofibrillar myopathy with early respiratory failure. J Neurol Neurosurg Psychiatry 2014;85:331-338.

3. Hackman P, Vihola A, Haravuori H, et al. Tibial muscular dystrophy is a titinopathy caused by mutations in TTN, the gene encoding the giant skeletal-muscle protein titin. Am J Hum Genet 2002;71:492-500.

4. Haravuori $\mathrm{H}$, Makela-Bengs $\mathrm{P}$, Udd B, et al. Assignment of the tibial muscular dystrophy locus to chromosome 2q31. Am J Hum Genet 1998;62:620-626.

5. Udd B, Partanen J, Halonen P, et al. Tibial muscular dystrophy: late adult-onset distal myopathy in 66 Finnish patients. Arch Neurol 1993;50:604-608.

6. Herman DS, Lam L, Taylor MR, et al. Truncations of titin causing dilated cardiomyopathy. N Engl J Med 2012; 366:619-628.

7. Peled Y, Gramlich M, Yoskovitz G, et al. Titin mutation in familial restrictive cardiomyopathy. Int J Cardiol 2014; 171:24-30.

8. Monreal G, Nicholson LM, Han B, et al. Cytoskeletal remodeling of desmin is a more accurate measure of cardiac dysfunction than fibrosis or myocyte hypertrophy. Life Sci 2008;83:786-794.

9. Orejarena LA, Vidaillet H, DeStefano F, et al. Paroxysmal supraventricular tachycardia in the general population. J Am Coll Cardiol 1998;31:150-157.

10. Semmler AL, Sacconi S, Bach JE, et al. Unusual multisystemic involvement and a novel BAG3 mutation revealed by NGS screening in a large cohort of myofibrillar myopathies. Orphanet J Rare Dis 2014;9:121. 


\section{Neurology}

\section{Cardiac involvement in hereditary myopathy with early respiratory failure: A cohort study}

Hannah E. Steele, Elizabeth Harris, Rita Barresi, et al.

Neurology 2016;87;1031-1035 Published Online before print August 10, 2016

DOI 10.1212/WNL.0000000000003064

\section{This information is current as of August 10, 2016}

\section{Updated Information \&} Services

References

Subspecialty Collections

\section{Permissions \& Licensing}

Reprints including high resolution figures, can be found at: http://n.neurology.org/content/87/10/1031.full

This article cites 10 articles, 2 of which you can access for free at: http://n.neurology.org/content/87/10/1031.full\#ref-list-1

This article, along with others on similar topics, appears in the following collection(s):

\section{All Genetics}

http://n.neurology.org/cgi/collection/all_genetics

All Neuromuscular Disease

http://n.neurology.org/cgi/collection/all_neuromuscular_disease

\section{CT}

http://n.neurology.org/cgi/collection/ct

\section{MRI}

http://n.neurology.org/cgi/collection/mri

Muscle disease

http://n.neurology.org/cgi/collection/muscle_disease

Information about reproducing this article in parts (figures,tables) or in its entirety can be found online at:

http://www.neurology.org/about/about_the_journal\#permissions

Information about ordering reprints can be found online: http://n.neurology.org/subscribers/advertise

Neurology ${ }^{\circledR}$ is the official journal of the American Academy of Neurology. Published continuously since 1951, it is now a weekly with 48 issues per year. Copyright @ 2016 American Academy of Neurology. All rights reserved. Print ISSN: 0028-3878. Online ISSN: 1526-632X.

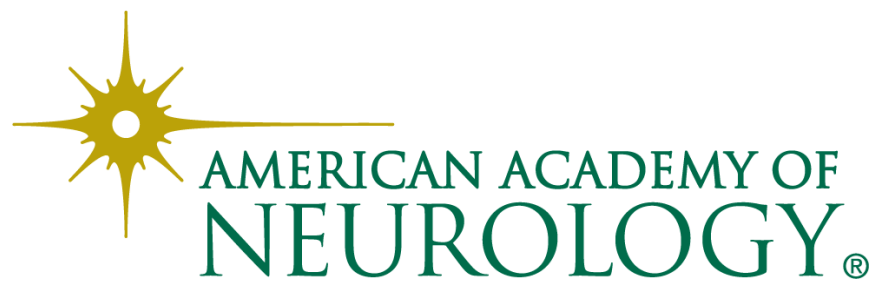

